\title{
Dedifferentiated Acinic Cell Carcinoma of the Parotid Gland With Myoepithelial Features
}

\author{
Simonetta Piana, MD; Alberto Cavazza, MD; Corrado Pedroni, MD; Rosa Scotti, MD; Luigi Serra, MD; Giorgio Gardini, MD
}

\begin{abstract}
- Dedifferentiated acinic cell carcinoma of the salivary gland is an uncommon variant of acinic cell carcinoma, characterized by the coexistence of both an usual lowgrade acinic cell carcinoma and a high-grade dedifferentiated component, as well as by an accelerated clinical course. We describe a case of acinic cell carcinoma of the parotid gland in a 67-year-old woman, which recurred 4 times after surgery and radiotherapy. The recurrences consisted of residual foci of acinic cell carcinoma intermingled with a high-grade epithelial proliferation; the latter was focally constituted by cells with morphologic and immunohistochemical features of myoepithelium.
\end{abstract}

(Arch Pathol Lab Med. 2002;126:1104-1105)

D edifferentiation is meant to be the morphologic coexistence of a low-grade and a high-grade malignancy; usually, a well-differentiated neoplasm loses, often in the recurrences, its line of morphologic differentiation and presents as a poorly differentiated malignancy. Originally reported in osteoskeletal pathology, the term dedifferentiation has been broadened to soft tissues ${ }^{1}$ and to salivary gland pathology. Acinic cell carcinomas are known to be able to "dedifferentiate" ${ }^{\prime 2-5}$; in addition, dedifferentiation occurring in 4 cases of adenoid-cystic carcinoma ${ }^{6-7}$ and in 1 case of epithelial-myoepithelial carcinoma ${ }^{8}$ has recently been described.

We report a case of dedifferentiated acinic cell carcinoma, in which the dedifferentiated component showed a myoepithelial phenotype. To the best of our knowledge, this phenomenon has never been described in dedifferentiated acinic cell carcinoma.

\section{REPORT OF A CASE}

A 46-year-old woman underwent a right radical parotidectomy, with preservation of the facial nerve, at another institution in 1977. In 1991, she presented with a well-circumscribed nodule, $2.5 \mathrm{~cm}$ in diameter, in the right parotid region and underwent a surgical resection. No residual salivary parenchyma was noted during surgery. The nodule was resected and the patient was treated subsequently with local radiotherapy. In 1997, a re-excision of a 1-cm nodule in the right parotid region was performed,

Accepted for publication November 7, 2001.

From the Department of Clinical Pathology, Division of Anatomic Pathology (Drs Piana, Cavazza, Scotti, Serra, and Gardini), and the Department of Otolaryngology (Dr Pedroni), Ospedale Santa Maria Nuova, Reggio Emilia, Italy.

Reprints: Simonetta Piana, MD, Servizio di Anatomia ed Istologia Patologica, Arcispedale Santa Maria Nuova, Via Risorgimento 81, Reggio Emilia, Italy (e-mail: piana.simonetta@asmn.re.it). with a partial resection of adjacent muscular and adipose tissue. In 1998, a $2.5-\mathrm{cm}$ nodule was found adherent to the right facial nerve; the facial nerve and the nodule were resected. In January 1999, the patient underwent another surgical intervention, with the resection of a $1.5-\mathrm{cm}$ nodule localized near the surgical scar, followed by radiotherapy. In August 1999, a nodule (2 cm in diameter) was noted next to the mandible angle on ultrasonography and was partially excised.

The patient is alive with a local recurrence; a radical surgical intervention has been planned.

\section{PATHOLOGIC FINDINGS}

The original resection, performed in 1977 at another institution, involved the superior and deep lobe of the right parotid gland. A review of 2 slides from this resection showed mild chronic inflammation with no evidence of neoplasm.

In all 5 subsequent interventions, from 1991 to 1999, the specimens grossly consisted of well-defined nodules, ranging from 3 to $0.6 \mathrm{~cm}$ in diameter, with a smooth surface. All excisions were marginal, and salivary parenchyma was not macroscopically apparent.

Microscopically, the nodules were only partially encapsulated and consisted of a proliferation of medium-sized polygonal cells, showing round nuclei with evident nucleoli and wide, granular, basophilic cytoplasm; nuclear atypia was minimal. Intermingled vacuolated cells were often noted. The neoplastic cells were arranged in a solid and microfollicular pattern. Periodic acid-Schiff stain highlighted cytoplasmic basophilic granules, which appeared diffuse and were resistant to diastase predigestion. This was the only neoplastic component present in the nodule excised in 1991 and in the first recurrence in 1997.

In the second, third, and fourth recurrences, the neoplasm consisted mainly of solid nests of atypical cells with large nuclei and abundant clear cytoplasm and with a high mitotic index. The cells failed to reveal any obvious duct differentiation. An additional feature was the presence of an irregular desmoplastic stroma associated with foci of myxoid stroma, in which the clear cells imperceptibly merged. Furthermore, a minor proliferation, morphologically superimposable to the one described in the first tumors, was present (Figure 1) and was highlighted by periodic acid-Schiff.

Immunohistochemical reactions were performed on the third and fourth recurrences using the avidin-biotin complex $(\mathrm{ABC})$ technique. Neoplastic cells showed strong and diffuse reactivity for S100 protein (Menarini, Italy; Figure 2) and focal positivity for smooth muscle actin (Menarini; Figure 3) and cytokeratin (Dakopatts A/S, Glostrup, Denmark; Figure 4). Chromogranin immunostaining was negative. 

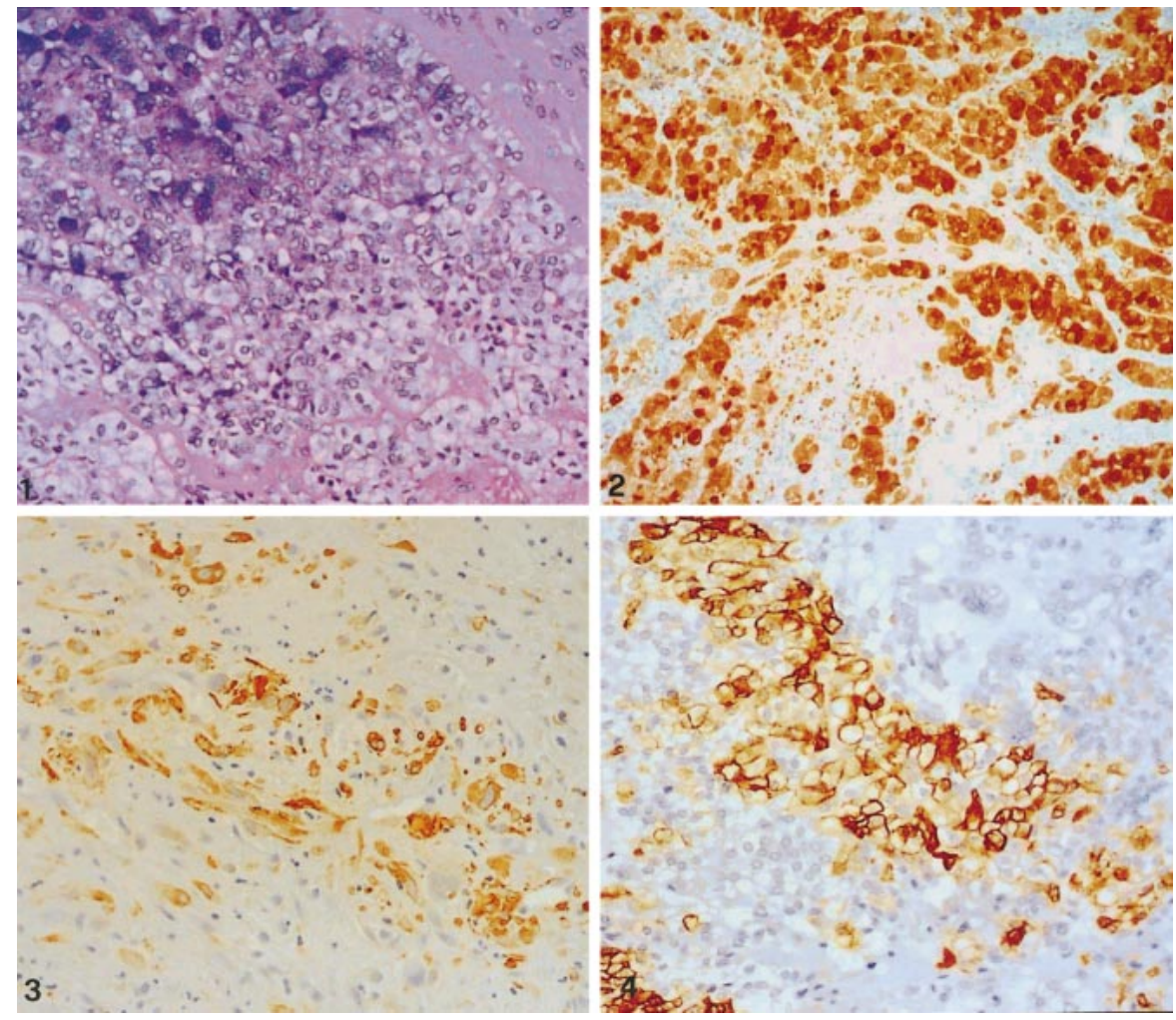

Figure 1. A minor component of classical acinic carcinoma is present but sharply separated from the clear cell proliferation (hematoxylin-eosin, original magnification $\times 100$ ).

Figure 2. The clear cells strongly immunoreact with $\$ 100$ protein (immunoperoxidase technique, original magnification $\times 100$ ).

Figure 3. $\alpha$-Smooth muscle actin immunostaining highlights the clear myoepithelial cells (immunoperoxidase technique, original magnification $\times 100$ ).

Figure 4. Focal positivity to cytokeratin AE1/ AE3 in neoplastic cells (immunoperoxidase technique, original magnification $\times 100$ ).

\section{COMMENT}

Since the original report by Stanley et al in $1988,{ }^{3}$ only a few cases of dedifferentiated acinic cell carcinoma have been described or briefly mentioned in the English literature. $2,3,9,10$

Dedifferentiated acinic cell carcinoma is composed of an usual acinic cell carcinoma and a poorly differentiated, highly malignant carcinomatous component in variable proportions. The high-grade carcinoma is often non-mucin-producing, but little is reported about its possible pattern of differentiation. The present report describes an acinic cell carcinoma that recurred with poorly differentiated areas and therefore can be designated "dedifferentiated" acinic cell carcinoma; immunohistochemistry revealed that the poorly differentiated areas were diffusely positive to S100 protein and focally positive to smooth muscle actin and cytokeratin. They had, in other words, a myoepithelial immunoprofile.

Myoepithelial differentiation is common in salivary gland neoplasms. By definition, it is present in epithelial-myoepithelial carcinoma, myoepithelioma, and myoepithelial carcinoma, and it often occurs in benign mixed tumors, adenoid cystic carcinoma, and salivary duct carcinoma. ${ }^{11,12}$ To our knowledge, no cases of myoepithelial features in a dedifferentiated acinic cell carcinoma have been reported to date.

Although dedifferentiation is always associated with tumor progression, little is known about the molecular events that regulate it; immunohistochemical and molecular studies on the expression of p53 oncoprotein have not provided conclusive results. ${ }^{2,6,8}$

The prognostic value of dedifferentiation is still to be defined, and statistically significant conclusions on the biological behavior of these tumors is not possible because of the small number of cases described. It is generally accepted that dedifferentiated carcinomas are associated with a poor clinical outcome, as they tend to involve the whole parotid gland and invade the facial nerve.

The current case expands the morphologic spectrum of dedifferentiated acinic cell carcinoma and emphasizes that myoepithelial differentiation should bring to mind differential diagnoses other than the usual myoepithelial salivary gland tumors. When such a myoepithelial differentiation is an expression of dedifferentiation, as in our case, its recognition may have prognostic significance.

\section{References}

1. Meis JM. "Dedifferentiation" in bone and soft tissue tumors: a histological indicator of tumor progression. Pathol Annu. 1991;26:37-62.

2. Henley JD, Geary WA, Jackson C, Wu CD, Gnepp DR. Dedifferentiated acinic cell carcinoma of the parotid gland: a distinct rarely described entity. Hum Pathol. 1997;28:869-873.

3. Stanley RJ, Weiland LH, Olsen KD, et al. Dedifferentiated acinic cell (acinous) carcinoma of the parotid gland. Otolaryngol Head Neck Surg. 1988;98: 155-161.

4. Batsakis JG, Luna MA, el-Naggar AK. Histopathologic grading of salivary gland neoplasms: acinic cell carcinomas. Ann Otol Rhinol Laryngol. 1990;99: 929-933.

5. Di Palma S, Corletto V, Lavarino C, et al. Unilateral aneuploid dedifferentiated acinic cell carcinoma associated with bilateral low-grade diploid acinic cell carcinoma of the parotid gland. Virchows Arch. 1999;434:361-365.

6. Cheuk WB, Chan JKC, Ngan RKC. Dedifferentiation in adenoid cystic carcinoma of salivary gland. Am J Surg Pathol. 1999;23:465-472.

7. Moles MA, Avila IR, Archilla AR. Dedifferentiation occurring in adenoid cystic carcinoma of the tongue. Oral Surg Oral Med Oral Pathol Oral Radiol Endod. 1999;88:177-180.

8. Fonseca I, Felix A, Soares J. Dedifferentiation in salivary gland carcinomas [letter]. Am J Surg Pathol. 2000;24:469-471.

9. Colmenero C, Patron M, Sierra I. Acinic cell carcinoma of the salivary gland: a review of 20 new cases. J Craniomaxillofac Surg. 1991;19:260-266.

10. Ellis Gl, Corio RI. Acinic cell carcinoma: a clinicopathologic analysis of 294 cases. Cancer. 1983;52:542-549.

11. Ellis GL, Auclair PL. Tumors of the Salivary Glands. Washington, DC: Armed Forces Institute of Pathology; 1996. Atlas of Tumor Pathology; 3rd series, fascicle 17

12. Prasad AR, Saavedra AT, Gown AM, Zarbo RJ. The myoepithelial immunophenotype in 135 benign and malignant salivary gland tumors other than pleomorphic adenoma. Arch Pathol Lab Med. 1999;123:801-806. 